\title{
Birdshot Chorioretinopathy treated with dexamethasone intravitreal implant and a biologic response modifier: a successful management
}

\section{Coriorretinopatia de Birdshot tratada com implante intravitreo de dexamentasona e imunobiológico: conduta bem sucedida}

Ricardo Evangelista Marrocos de Aragão ${ }^{1}$. Ieda Maria Alexandre Barreira ${ }^{2}$. Cristina Muccioli ${ }^{3}$. Francisco Holanda Oliveira Neto ${ }^{4}$. Barbara Lorena Alves Arrais 5 . Francisco George Magalhães de Oliveira ${ }^{6}$ Gustavo Jose Arruda Mendes Carneiro5.

1 Doutor em medicina pela Universidade de Regensburg, Ratisbona, Alemanha, Preceptor de Retina do Hospital Universitário Walter Cantídio (HUWC), Professor voluntario de oftalmologia da Universidade Federal do Ceará (UFC), Fortaleza, Ceará, Brasil. 2 Oftalmologista do Centro Integrado de Diabetes e Hipertensão, Fortaleza, Ceará, Brasil. 3 Doutorado em Medicina (Oftalmologia) pela Universidade Federal de São Paulo (UNIFESP), Professora de oftalmologia da Universidade Federal de São Paulo (UNIFESP), São Paulo, São Paulo, Brasil. 4 Residência em oftalmologia, Hospital Universitário Walter Cantídio (HUWC), Fortaleza, Ceará, Brasil. 5 Residente de oftalmologia, Hospital Universitário Walter Cantídio (HUWC), Fortaleza, Ceará, Brasil. 6 Médico, Hospital Universitário Walter Cantídio (HUWC), Fortaleza, Ceará, Brasil.

\section{ABSTRACT}

Birdshot chorioretinopathy is an organ-specific, potentially blinding chronic of bilateral inflammation of the posterior eye segment. It is seen mainly in persons who have the HLA-A29 haplotype. The diagnosis remains clinical and is based in his hallmark, which is the presence of multiples white dots throughout the fundus, resembling a shotgun pattern. The immune mechanisms involved in its pathogenesis remains unclear and the long-term outcome is guarded. However, the use of immunosuppressive agents and newer therapies demonstrated control of the inflammation and is a hope mainly in refractory cases. We report a case of Birdshot chorioretinopathy treated successfully with steroids and immunosuppressive agents.

Keywords: Uveitis. Birdshot chorioretinopathy. HLA-A29. Retinal vasculitis. Anti-inflammatory agents.

\section{RESUMO}

Coriorretinopatia de Birdshot é uma inflamação ocular crônica, bilateral do segmento posterior do olho que pode levar a cegueira. É associada ao haplótipo HLA-A29. O diagnóstico é clínico em suas alterações típicas no fundo de olho, múltiplos pontos brancos lembrando o padrão de tiro de espingarda. O mecanismo inume na patogênese da doença não está claro e o prognóstico visual é reservado. Entretanto, o uso de agentes imunossupressores e novas terapias têm demonstrado controle da inflamação e representa uma esperança nos casos refratários. Reportamos um caso de Birdshot tratado com sucesso utilizando esteroides e imunossupressores.

Palavras-chave: Uveites. Coriorretinioatia de birdshot. HLA-A29. Vasculite retiniana. Agentes anti-inflamatórios.

Corresponding Author: Ricardo Evangelista Marrocos de Aragão, Rua Osvaldo Cruz, 2335, Dionísio Torres, Fortaleza, Ceará. CEP: $60125-151$. Telefone: +55 85 9137-9313. E-mail: ricardomarrocos@yahoo.com

Conflict of interests: The authors have no conflicts of interest to declare.

Received: 07 Set 2016; Revised: 20 Jan 2017; Accepted: 20 Jan 2017. 


\section{INTRODUCTION}

Birdshot chorioretinopathy (BSCR) is a chronic, uncommon, bilateral posterior uveitis. It is mostly seen in patients of Caucasian origin in their $5^{\text {th }}$ decade of life. There is a strong genetic association with the human leukocyte antigen HLA-A29. ${ }^{1}$ The first report of BSCR was in 1949 by Franceschaetti and Babel described as candle wax spot chorioretinopathy. Later, the term has changed to "birdshot retinochoroidopathy". Its hallmark is multiple, small, white spots resembling a shotgun pattern. ${ }^{2}$ Vitritis, cystoids macular oedema (CMO), retinal vasculitis, and disc oedema may be present. Vascular attenuation and optic disc pallor may be seen in final stage. Mostly patients with BSCR have complains of insidious onset of floaters, proceeding or not with reduced acuity mainly caused by CMO. Nyctalopia, photopsia, visual field constriction and color vision deficits are reported as well. ${ }^{3}$

\section{CASE REPORT}

A 51-year-old man noted decreased vision in both eyes for three months. There was no significant ocular history. In his medical history he has Hashimoto thyroiditis. Family history was unremarkable.

On examination his best-corrected visual acuity (BCVA) was 20/40 OD, 20/20 OS. Anterior chamber show no cells in both eyes. The pupilary reactions were normal. Intraocular pressure( IOP) was $15 \mathrm{mmHg}$ in both eyes. Vitreous revealed $1+$ cell in both eyes. Fundus evaluation shows multiple small yellowish deep choroidal lesions and vascular sheathing in both eyes (Figure 1).

Fluorescein angiogram (Heidelberg Engineering, Germany) of the both eyes showed leakage from the disc and the retina veins of both eyes and also some blocked fluorescence from the deep lesions in the early phase and late stain.(Figure 2) Indocianine green angiogram (Heidelberg Engineering, Germany) reveals blocked fluorescence in areas of the choroidal lesions. Goldman and automated visual fields showed generalized constriction of the peripheral visual field and enlargement of the blind spot in both eyes. Electroretinogram revealed an a-wave well preserved, whereas b-wave exhibited a reduction in amplitude and an increased latency time in both eyes. Optical coherence tomography (OCT (Heidelberg Engineering, Germany)) exhibited a epiretinal membrane formation and disruption of the IS-OS/ellipsoid layer with some retinal disorganization and generalized thinning of the choroid and outer retina in both eyes. Based on these findings a presumptive diagnosis of birdshot chorioretinopathy was made. Visual field testing (Humphrey Field Analyzer, Carl Zeiss Meditec INC., Dublin, CA) showed generalized constriction of the peripheral visual field in both eyes (Figure 3).

Laboratory studies showed later normal angiotensin-coverting enzyme levels, normal complete blood count, normal serum protein electrophoresis, and absent Lyme and syphilis antibodies (FTA-ABS and VDRL); quantiferon testing for prior tuberculosis exposure was normal, chest x-ray was unremarkable, systemic lupus was excluded, no systemic disease was found. HLA class 1 typing was positive for HLA-A29. A definitive diagnosis of Birdshot was thus confirmed and the patient started on systemic steroids and low-dose regiment of cyclosporine $(5 \mathrm{mg} / \mathrm{kg} /$ day) and one month later changed to adalimumab due to complications with cyclosporin.

Figure 1. Fundus photography showing multiple small yellowish deep choroidal lesions and vascular sheathing in both eyes.
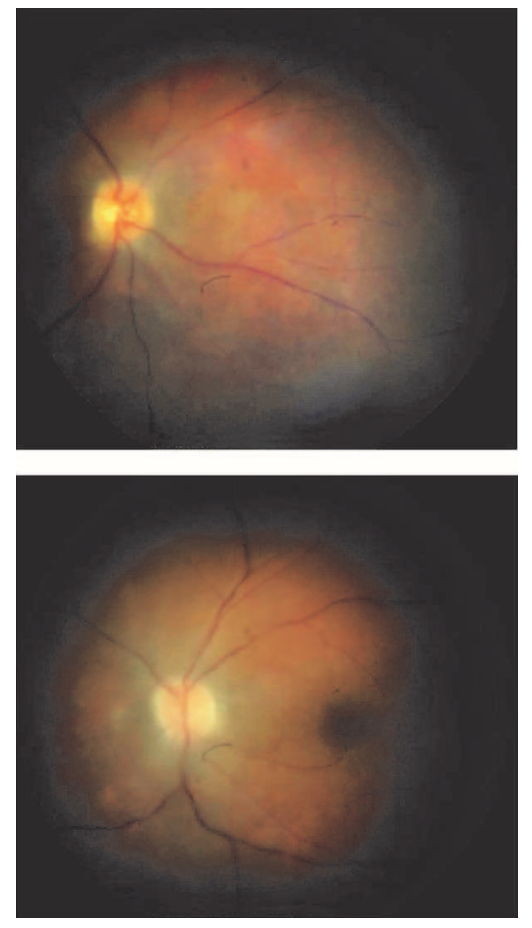

Figure 2. Fluorescein angiogram revealing late stain of the white dots and leakage from disc and retina veins in both eyes.

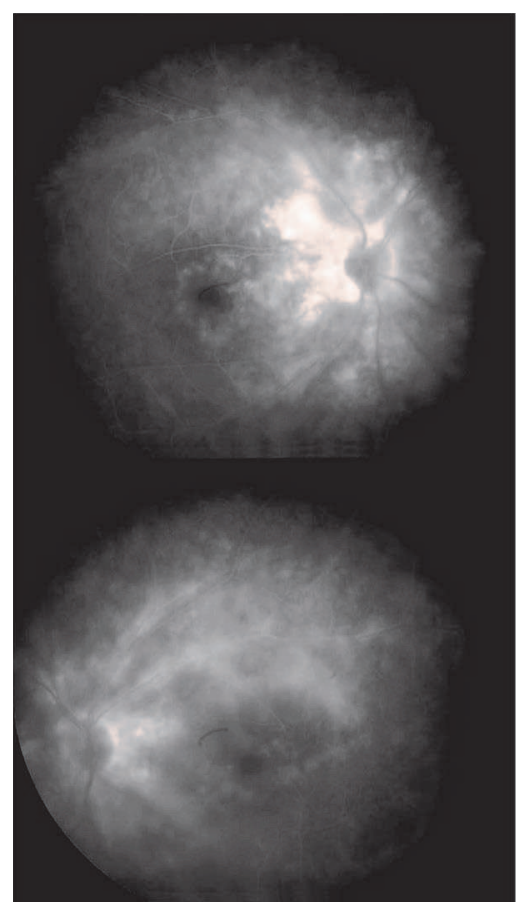


Figure 3. Visual field testing showing generalized constriction of the peripheral visual field in both eyes.
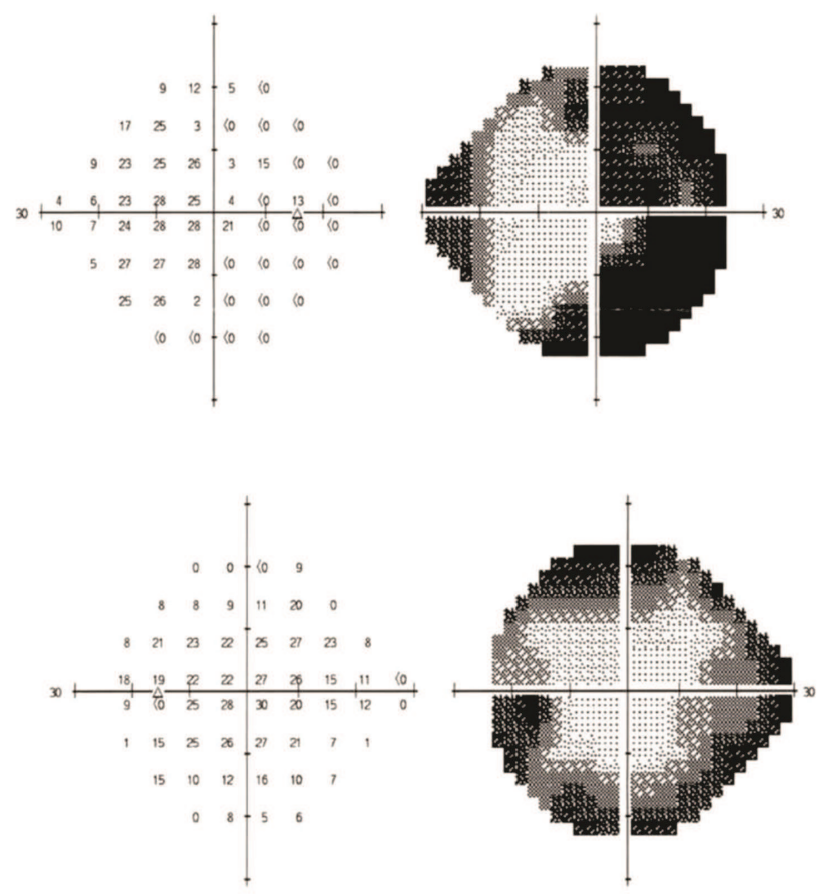

One month later his visual acuity on the right eye decreased to $20 / 60$, OS remained $20 / 20$. The OCT scanning showed a serous retinal detachment (Figure 4.1) and also visual field alterations in the OD, no involvement of the OS was seen. He was treated with dexamethasone intravitreal implant in the OD. After one month his BCVA was 20/40 with improvement of the serous retinal detachment. (Figure 4.2) The OD developed a visually significant cataract and elevated IOP, 3 months after the implant, when phacoemulsification was performed and IOP was controlled with drops.

Figure 4. 1.OCT showing a neurosensory retinal detachment and subretinal fluid in the right eye berofe treatment. 2.OCT showing improvement of the neurosensory retinal detachment in the right eye.
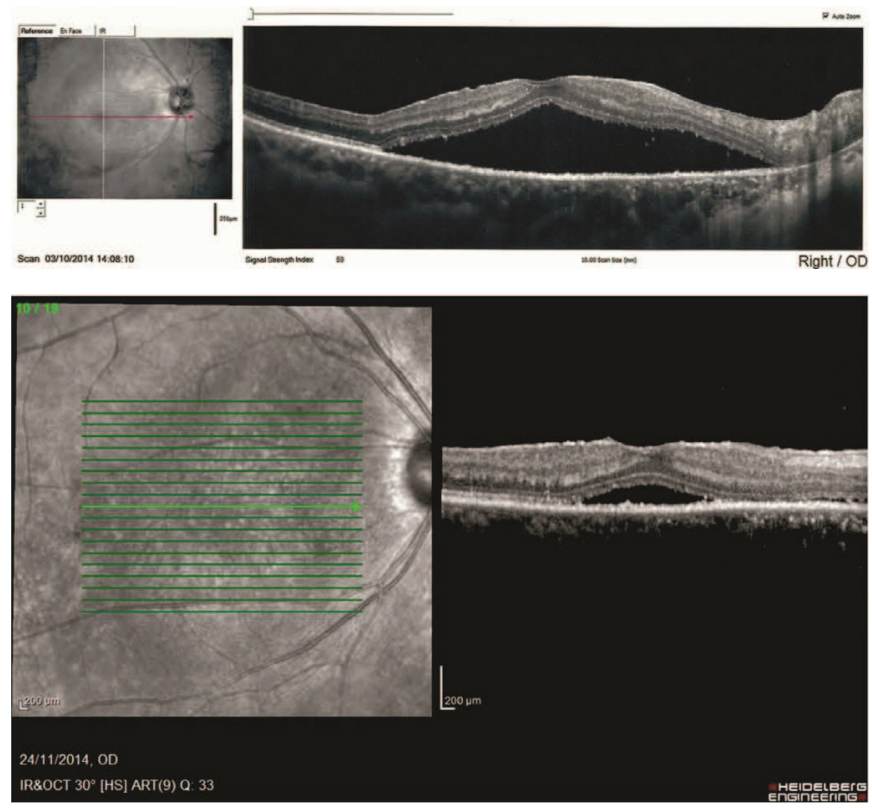

Follow-up over a period of 18 months showed a marked improvement in his symptom, fundus examination, OCT and visual field still do not show any further lesions. The systemic steroid was tapped and patient is still in treatment with adalimumab. The patient provided written inform consent.

\section{DISCUSSION}

Birdshot chorioretinopathy (BSCR), is a chronic, Idiopathic bilateral posterior uveitis. It is thought to be a predominantly ocular disease, seen in otherwise healthy patients without systemic disease associations. ${ }^{4}$ BSCR is an autoimmune condition, nevertheless its pathogenesis remains unknown. There is a strong association with the HLA-A29, human leukocyte antigen, with the disease, which has a sensitivity of $96 \%$ and a specificity of $93 \%$, the haplotype is confirmatory rather than diagnostic. Retinal autoimmunity is thought to play a key role in the pathogenesis of BSCR. Infectious agent may play a role by enhancing the expression by the HLA-A29 molecule to lymphocytes. ${ }^{5}$

Most of the patients with BSCR have complaints of blurred vision, floaters, and photopsias by the onset. Blurred vision may initially involve only one eye, but over the time the other eye is almost always affected, albeit asymmetrical. Most have vision of $20 / 40$ or better. However, visual complaints are not infrequently dramatically out of proportion to the measured acuity in contrast of good visual acuity. Spite of normal vision, severe nictalopia may be present. Color vision or visual field alteration has been also described. The anterior segment usually has minimal inflammation without prominent keratic precitiptates, however, dense vitreous opacity is usually present. ${ }^{6,7}$ Secondary cystoid macular oedema and optic disc oedema, may be associated with retinal vascular leakage. The hallmark of the fundus is discrete, cream colored or depigmented; ${ }^{2}$ spots throughout the postequatorial fundus, resembling a shotgun pattern.

The lesions may be distributed in a diffuse pattern, macular sparing, macular predominance, and asymmetric. In ht late stage of the disease, in a small number of the patients, optic nerve atrophy may occur. ${ }^{8}$

A laboratory work-up based on a complete ocular exam and review of systems to rule out likely infectious and noninfectious causes of uveitis is essential at presentation. ${ }^{5}$

Fluorescein angiography (FA) in the early stage, in most cases of BSCR, the spots are not evident, becoming apparent in the venous phase, as faint hyperfluorescent flecks which did not increase in the late phase. Retinal vascular leakage is a very common finding on FA, and cystoid macular oedema may be present. Optic disc may also show blurred margins due to lesions adjacent or due to disc swelling. ${ }^{9}$ The most common finding visual field testing are generalized constriction of the peripheral visual field, central and paracentral scotomata, enlarged blind spot associated either or with optic disc oedema or a circumpapillary birdshot lesions. Indocyanine green angiography (ICG) shows multiple hypofluorescent spots, which are typically more numerous than those seen on clinical examination or on FA. ${ }^{10}$ By optical coherence tomography (OCT), macular thinning and loss of the inner 
segment/outer segment junction may be visualized. ${ }^{5}$ Fundus autofluorescence (FAF) in BSRC may disclose discrete areas of hypoautofluorescence due to RPE atrophy; thought there is no correspondence between the spots seen in FAF and the birdshots lesions seen biomicroscopically. Electroretinography typically reveals a disproportionate decrease in b-wave amplitude compared with a-wave amplitude in the early stages of the disease. A defect in the blue-yellow and red-green spectrum, may seen in the color vision test. ${ }^{9}$

In the differential diagnosis all cause of posterior uveitis must be rule out; as well white dot syndromes, systemic infections and noninfectious disease that produce panuveitis and light-colored fundus lesions at some stage in their clinical course, including parsplanitis, Vogt-Koyanagi-Harada syndrome, sympathetic ophthalmia, ocular histoplasmosis syndrome, and specially sarcoidosis.

The initial treatment consists in administration of systemic corticosteroids, with early introduction of corticosteroid-sparing immunomodulators. Periocular and intravitreal corticosteroid injections are useful as adjunctive therapy in managing cystoid macular oedema and inflammatory recurrences. Intravitreal fluocinolone acetonide implant can be an alternative in patients with systemic therapy intolerance. ${ }^{6}$ The dexamethasone intravitreal implant is reported to be effective in both adult and pediatric uveitis, but the side effect profile of multiple implants is not yet clear and further data are needed, including in BSCR. The use of cyclosporine and low-dose methotrexate for treatment in BSCR has been documented in some studies. Mycophenolate mofetil may be

\section{REFERENCES}

1. Menezo V, Taylor SR. Birdshot uveitis: current and emerging treatment options. Clin Ophthalmol. 2014;8:73-81.

2. Faia LJ. Gender differences in birdshot chorioretinopathy and the white dot syndromes: do they exist? J of Ophthalmol. 2014;2014:1-10.

3. Holder GE, Robson AG, Pavesio C, Graham EM. Electrophysiological characterization and monitoring in the management of birdshot chorioretinopathy. $\mathrm{Br} \mathrm{J}$ Ophthalmol. 2005;89(6):709-18.

4. Zucchiatti I, Miserocchi E, Sacconi R, Bandello F, Modorati G. HLA-A29-positive uveitis: birdshot chorioretinopathy, what else? Case Rep Ophthalmol. 2013;4(3):287-93.

5. Vitale AT. Birdshot Retinochoroidopathy. In: Vitale AT, Foster CS, editors. Diagnosis e Treatment of Uveitis. Nova Deli: J B Medical Publisher LTD; 2013. p. 982-1004. a good first choice of second-line immunosuppressive agent, since cyclosporine is not ideal for long-term use because of its renal toxic effects, especially in a population with BSCR, which are typically older at the time of diagnosis compared with other patients with uveitis. The use of second-line agents like mycophenolate mofetil may stabilize the disease during the acute phase and is well tolerated. Biologic response modifiers agents, contrary to immunosuppressive agents, modulate inflammation by targeting specific receptors which offer a more specific targeted suppression of immune effectors response and tissue damage. Therefore, they are useful alternative in patients no responsive to conventional immunosuppressive therapy. Infliximab, a chimeric monoclonal antibody targeted against the tumor necrosis factor TNF-a inhibitors, can be a alternative in the treatment of patients with different types of refractory uveitis including BSCR. ${ }^{1}$ Novel biologic agents like Daclizumab which is a humanized immunoglobulin $G$ monoclonal antibody directed against the CD25 subunit of the IL-2 receptor showed its effectiveness in suppressing intraocular inflammation. ${ }^{1}$ Adalimumab that was used in our patient, is a fully humanized monoclonal IgG1 antibody directed against TNF-a, has been shown to be effective as infliximab in controlling inflammation, with success rates of $100 \%$ in adults patients with Behcet uveitis, posterior uveitis, and panuveitis.

Since this condition is relatively uncommon and has a slow progression, all data recorded is limited to small series of mainly retrospective studies and limited follow-up. Further studies are needed to evaluated long-term follow-up and whether any single agent is superior to control the disease.

6. Skuta GL, Cantor LB, Weiss JS. Basic and clinical science course. Section 9. [Internet]. San Francisco: American Academy of Ophthalmology; 2012 [Cited 2012 Out 12]. Available from: http:// www.aao.org

7. Giuliani G, Hinkle DM, Foster CS. The spectrum of fundus autofluorescence findings in birdshot chorioretinopathy. J Ophthalmol. 2009;2009:1-5.

8. Ryan SJ. Retina. 5. ed. Los Angeles: Elsevier; 2013.

9. Priem HA, Oosterhuis JA. Birdshot chorioretinopathy: clinical characteristics and evolution. Br J Ophthalmol. 1988;72(9):646-59.

10. Gasch AT, Smith JA, Whitcup SM. Birdshot retinochoroidopathy. Br J Ophthalmol. 1999;83(2):241-49.

\section{Como citar:}

Aragão RE, Barreira IM, Muccioli C, Oliveira FH Neto, Arrais BL, Oliveira FG, et al. Birdshot Chorioretinopathy treated with dexamethasone intravitreal implant and a biologic response modifier: a successful management. Rev Med UFC. 2017 set-dez;57(3):54-57. 